\title{
Epidemiology of Leprosy in Childhood: A Retrospective Study
}

\section{Rusmawardiana ${ }^{*}$, Fifa Argentina ${ }^{1}$, Indri Widya Sari1}

${ }^{1}$ Department of Dermatology and Venereology, Faculty of Medicine Universitas Sriwijaya, Palembang. Indonesia

\section{A R T I C L E I N F O \\ Keywords: \\ Leprosy \\ Children \\ Epidemiology}

\section{*Corresponding author:}

Rusmawardiana

\section{E-mail address:}

rusmawardiana@fk.unsri.ac.id

All authors have reviewed and approved the final version of the manuscript.

https://doi.org/10.32539/bsm.v5i5.309

\begin{abstract}
A B S T R A C T
Background: Children are the group most susceptible to Mycobacterium leprae infection. The proportion of new leprosy cases in children is indicator of successful leprosy elimination program from World Health Organization (WHO), so this study would like to know the epidemiology of pediatric leprosy at Dermatology and Venereology Polyclinic, Dr. Mohammad Hoesin Palembang. Methods: Retrospective study of all new cases of leprosy in children (0-17 years) who came to Dermatology and Venereology Polyclinic, Dr. Mohammad Hoesin Palembang from January 2017 to December 2020. Results: There were 10 pediatric patients $(7.58 \%)$ from 132 new leprosy cases. Most cases $(40 \%)$ were in the $15-17$ age group. There are more male than female. Most types of leprosy are BL $(60 \%)$ followed by TT $(20 \%)$. Manifestations of hyperpigmented skin patches and nervous disorders, grade 1 disability, and type 2 leprosy reactions are mostly found in type BL leprosy. The duration of illness 6-12 months has a grade 1 disability (30\%). The history of positive contact came from same household in 3 cases $(30 \%)$ with 7 people $(70 \%)$ domiciled in Palembang. All cases received Multidrug Therapy (MDT) treatment according to WHO guidelines. Conclusion: Found 10 new cases of leprosy in children in Dermatology and Venereology Polyclinic Dr. Moh. Hoesin Palembang for four years, especially in the 15-17 age group, with the most cases being type BL leprosy. Household contact still plays an important role in leprosy transmission.
\end{abstract}

\section{Introduction}

Leprosy is a chronic infectious disease caused by Mycobacterium leprae. This disease causes skin, mucosal, and nerve disorders. This disease can affect all ages, although cases in infants are rare. Leprosy is a major health problem in developing countries. ${ }^{1}$

Based on data from WHO in 2019, the number of leprosy cases in the world was 202,185 cases. ${ }^{2}$ More than 10,000 new cases occurred in three countries, namely Brazil, India, and Indonesia. 1,2 Meanwhile, new cases in children were 14,981.2 In endemic areas, 9 out of 100 new leprosy cases are currently found in children. In Indonesia, there were 17,439 new cases of leprosy during 2019, and $12.01 \%$ were children. ${ }^{2,3}$ Based on data from Ministry of Health in Indonesia during 2018, new cases of leprosy in children at South Sumatra were $7.58 \%$.

According to the law of Indonesia, number 23 of 2002 concerning child protection, a child is someone who is not yet 18 (eighteen) years old, including children who are still in the womb. Children are believed to be the group most vulnerable to contracting M. leprae because of their low immunity and exposure to family contacts. Leprosy can mimic other diseases, appearing as hypopigmented spots on the face or arms as well as neuromuscular disorders such as sensory disorders or muscle weakness. The clinical feature and the grading of severity of leprosy are largely determined by the patient's immune response, especially the cellular immune response. The development of the immune system in children is relatively less than 
adults. Early diagnosis and treatment are important in preventing disability, deformity disorders, and psychosocial burden due to leprosy. ${ }^{4}$

This retrospective study aims to determine the epidemiology of leprosy in children at Dermatology and Venereology Polyclinic, Dr. Moh. Hoesin General Hospital Palembang.

\section{Methods}

The study was conducted retrospectively by taking data from all new leprosy patients from medical records at the Dermatology and Venereology Polyclinic, Dr. Moh. Hoesin Palembang during the period January 2017 to December 2020 (4 years). Data were collected from children aged 0-17 years, including gender, age, type of leprosy, skin manifestations, neurological dysfunction, leprosy reactions, duration of illness, source of contact, domicile, and medication. This study has received approval from the ethics committee with No.01 / kepkrsmh / 2021.

\section{Results}

The number of new leprosy patients seeking treatment at the Dermatology and Venereology Polyclinic, Dr. Moh. Hoesin Palembang for 4 years from January 2017 to December 2020 was 132 people and 10 people $(7.58 \%)$ were children aged 0-17 years (Table $1)$. The number of men is more, namely 6 people $(60 \%)$ and 4 women $(40 \%)$.

The Ministry of Health of the Republic of Indonesia categorizes children into 4 age groups. Patients aged 15-17 years were the largest age group found in this study, namely 4 children (40\%) leprosy type BL, followed by the 5-9 year age group of 3 children (30\%) and the 10-14 year age group as many as 21 children (20\%) and 0-4 years (10\%) as shown in Table 2.

Based on the classification of leprosy according to WHO, it was found that MB type leprosy was more than PB type in both the male and female groups, namely 4 people (40\%) in male group and 3 people $(30 \%)$ in female group (Table 3). Meanwhile, the distribution of leprosy based on Ridley and Jopling's criteria showed that most patients were BL type, namely 6 people $(60 \%)$ as shown in Table 3.

Based on WHO guidelines, skin manifestations can include white patches (hypopigmentation) or red spots (erythema) accompanied by hypoesthesia. Another characteristic is brownish (hyperpigmented) spots, in the form of macules, papules, nodules, and plaques. Hypoesthesia ulcers can also be found.2,5 The manifestation of skin disorders in the form of hyperpigmented patches was found mostly in type $\mathrm{BL}$, amounting to 3 people $(20 \%)$. Erythematous nodules were also found mostly in type BL, amounting to 3 people (20\%), as shown in Table 4.

The cardinal sign of leprosy according to WHO can be marked by thickening of peripheral nerves accompanied by hypoesthesia or weakness of the muscles supplied by peripheral nerves. Anhidrosis and thermosensitivity disorders can also occur. ${ }^{2}$ Five patients did not experience nerve function disorders, either sensory, motoric, or autonomic. Nerve function disorders were found in 5 people. Sensory disorder in the form of hypesthesia in one type $\mathrm{BL}$ patient. Impaired sensory and motoric nerve function in $2 \mathrm{BL}$ type patients, as well as 1 person (11.11\%) in LL and TT types, are shown in Table 5.

The grading of leprosy disability according to WHO is divided into grades 0,1 , and 2 leprosy defects if there are no abnormalities in the eyes, palms, and feet due to leprosy. Grade 1 leprosy disability if there is damagedue to leprosy (anesthesia to the cornea, but the visual disturbance is not severe (> 6/60). Anesthetic and muscle weakness are found in the palms and feet, but there is no visible disability/damage due to leprosy. Grade 2 if found lagophthalmos, iridocyclitis, opacity in the cornea, and severe visual disturbances $(<6 / 60)$. Disabilities/visible damage is found due to leprosy, for example, ulcers, finger, and legs paralyzed (50\%). Five people (50\%) have grade 0 leprosy disability. Five people (50\%) have grade 1 leprosy disability with sensory and motoric disorder. There were 3 people (30\%) of the BL type, 1 person (10\%) the TT type, and 1 person (10\%) the LL type. There were no patients with grade 2 disability as shown in Table 6. 
Leprosy reactions are divided into type 1 and type 2 . Type 1 leprosy reactions are characterized by red, swollen, shiny, warm skin patches, may be accompanied by edema of the hands and feet. Type 2 leprosy reactions are characterized by reddish, tender, tender nodules, and ulceration. Lucio phenomenon is a severe type 2 leprosy reaction, characterized by erythematous plaques accompanied by purpura, bullae that quickly become ulcerated from necrosis. ${ }^{1,5}$ Total of 6 people $(60 \%)$ do not experience any reactions. Type 2 reactions occurred in 3 people (30\%) with BL type, and Lucio phenomenon in 1 person (10\%) with LL type.

Based on the complaints experienced by patients until they seek treatment, they are grouped into 3-time ranges, namely < 6 months, 6-12 months, and $>12$ months. In the study, the data obtained from 6-12 months of illness were 3 people $(30 \%)$ with grade 1 leprosy disability.
Based on the source of leprosy transmission through close and long contact, they are grouped into household contacts, neighbors, and others. Based on the history of the source of the patient's contact, it was found that there were no known data as many as 7 people $(70 \%)$, as many as 3 people (30\%) had close contact with householders. Based on the distribution of the patient's residence, it is divided into domiciles in Palembang and outside Palembang. Data was obtained that the number of patients residing in Palembang was more than 7 people $(70 \%)$ while from outside Palembang there were 3 people (30\%).

Based on the treatment history and type of leprosy (Table 3), it was found that all leprosy patients had never been treated, namely 10 people (100\%). Treatment with MDT PB was given to 3 people (30\%), and MDT MB to 7 people (70\%).

Table 1. Distribution of leprosy cases in children per year

\begin{tabular}{lccc}
\hline \multirow{2}{*}{ Year } & \multicolumn{2}{c}{ Leprosy Cases } & \multirow{2}{*}{ Total n (\%) } \\
\cline { 2 - 3 } & $\mathbf{0 - 1 7 \text { years old }}$ & $\geq \mathbf{1 8}$ years old & \\
\hline 2017 & $7(5.30 \%)$ & $30(22.73 \%)$ & $37(28.03 \%)$ \\
2018 & $2(1.52 \%)$ & $33(25 \%)$ & $35(26.52 \%)$ \\
2019 & $1(0.76 \%)$ & $39(29.54 \%)$ & $40(30.30 \%)$ \\
2020 & 0 & $20(15.15 \%)$ & $20(15.15 \%)$ \\
\hline Total & $10(7.58 \%)$ & $122(92.42 \%)$ & $132(100 \%)$ \\
\hline
\end{tabular}

Table 2. Classification of leprosy according to age group of new leprosy patient aged 0-17 years

\begin{tabular}{|c|c|c|c|c|c|}
\hline \multirow{2}{*}{$\begin{array}{l}\text { Classification } \\
\text { of leprosy }\end{array}$} & \multicolumn{4}{|c|}{ Age group (years old) } & \multirow{2}{*}{ Total n $(\%)$} \\
\hline & $0-4$ & $5-9$ & $10-14$ & $15-17$ & \\
\hline TT & 0 & $1(10 \%)$ & $1(10 \%)$ & 0 & $2(20 \%)$ \\
\hline BT & 0 & $1(10 \%)$ & 0 & 0 & $1(20 \%)$ \\
\hline BB & 0 & 0 & 0 & 0 & 0 \\
\hline $\mathrm{BL}$ & $1(10 \%)$ & 0 & $1(10 \%)$ & $4(40 \%)$ & $6(60 \%)$ \\
\hline LL & 0 & $1(10 \%)$ & 0 & 0 & $1(10 \%)$ \\
\hline Total & $1(10 \%)$ & $3(30 \%)$ & 2 (20\%) & $4(40 \%)$ & 10 (100\%) \\
\hline
\end{tabular}


Table 3. Classification of leprosy according to sex of new leprosy patients aged 0-17 years

\begin{tabular}{|c|c|c|c|c|c|c|c|c|}
\hline \multirow{2}{*}{ Sex } & \multicolumn{2}{|c|}{ PB type } & \multirow{2}{*}{ Total PB } & \multicolumn{3}{|c|}{ MB type } & \multirow{2}{*}{$\begin{array}{c}\text { Total } \\
\text { MB }\end{array}$} & \multirow{2}{*}{$\begin{array}{l}\text { Total } \\
\text { n (\%) }\end{array}$} \\
\hline & TT & BT & & BB & BL & LL & & \\
\hline Male & 2 & 0 & $2(20 \%)$ & 0 & 3 & 1 & $4(40 \%)$ & $6(60 \%)$ \\
\hline Female & 0 & 1 & $1(10 \%)$ & 0 & 3 & 0 & 3 (30\%) & 4 (40\%) \\
\hline Total & 2 & 1 & $3(30 \%)$ & 0 & 6 & 1 & 7 (70\%) & $10(100 \%)$ \\
\hline
\end{tabular}

Table 4. Manifestations of skin disorders based on the type of leprosy

\begin{tabular}{lcccccc}
\hline $\begin{array}{l}\text { Manifestations of } \\
\text { skin disorders }\end{array}$ & \multicolumn{7}{c}{ Type of leprosy n (\%) } & Total n (\%) \\
\cline { 2 - 6 } & TT & BT & BB & BL & LL & \\
\hline $\begin{array}{l}\text { Hyperpigmentation } \\
\text { patch }\end{array}$ & 0 & 0 & 0 & $3(20 \%)$ & $1(6.67 \%)$ & $4(26.67 \%)$ \\
Hypopigmentation & $1(6.67 \%)$ & $1(6.67 \%)$ & 0 & $1(13.33 \%)$ & 0 & $3(20 \%)$ \\
Erythematous plaque & $1(6.67 \%)$ & 0 & 0 & $2(13.33 \%)$ & 0 & $3(20 \%)$ \\
Erythematous nodules & 0 & 0 & 0 & $3(20 \%)$ & $1(6.67 \%)$ & $4(26.67 \%)$ \\
Ulcer & 0 & 0 & 0 & 0 & $1(6.67 \%)$ & $1(6.67 \%)$ \\
\hline Total & $2(13.33 \%)$ & $1(6.67 \%)$ & 0 & $9(60 \%)$ & $3(20 \%)$ & $15(100 \%)$ \\
\hline
\end{tabular}

Table 5. Nerve function disorders based on the type of leprosy

\begin{tabular}{|c|c|c|c|c|c|c|}
\hline \multirow{2}{*}{ Nerve function disorders } & \multicolumn{5}{|c|}{ Type of leprosy $n(\%)$} & \multirow{2}{*}{ Total n $(\%)$} \\
\hline & TT & BT & BB & BL & $\mathbf{L L}$ & \\
\hline Sensory (anesthesia) & $1(11.11 \%)$ & 0 & 0 & $3(33.33 \%)$ & $1(11.11 \%)$ & $5(55.56 \%)$ \\
\hline $\begin{array}{l}\text { Motoric (muscle } \\
\text { weakness) }\end{array}$ & $1(11.11 \%)$ & 0 & 0 & $2(22.22 \%)$ & $1(11.11 \%)$ & $4(44.44 \%)$ \\
\hline Autonomic (anhidrosis) & 0 & 0 & 0 & 0 & 0 & 0 \\
\hline Total & $2(22.22 \%)$ & 0 & 0 & $5(55.56 \%)$ & $2(22.22 \%)$ & $9(100 \%)$ \\
\hline
\end{tabular}

Table 6. Disability grading based on the type of leprosy

\begin{tabular}{lcccccc}
\hline \multirow{2}{*}{ Disability grading } & \multicolumn{7}{c}{ Type of leprosy n (\%) } & Total n (\%) \\
\cline { 2 - 5 } & TT & BT & BB & BL & LL & $5(50 \%)$ \\
Grade 0 & $1(10 \%)$ & 1 & 0 & $3(30 \%)$ & 0 & $5(50 \%)$ \\
Grade 1 & $(10 \%)$ & 0 & $3(30 \%)$ & $1(10 \%)$ & 0 \\
Grade 2 & $1(10 \%)$ & 0 & 0 & 0 & 0 & $10(100 \%)$ \\
\hline Total & 0 & 0 & 0 & $6(60 \%)$ & $1(10 \%)$ & 1000 \\
\hline
\end{tabular}




\section{Discussion}

Based on reports from 120 countries, it shows that out of a total of 202,185 new cases of leprosy diagnosed during 2019. From 14,981 were children, representing $7.4 \%$ of all new cases reported annually. More than $80 \%$ of new cases globally are from India, Brazil, and Indonesia. Studies in India and Brazil report 25\% of cases of children $<15$ years old. ${ }^{2}$

Based on data from the Indonesian Ministry ofHealth during the 2013-2017 period, the detection rateof new leprosy cases in children ranges from 11.05-11.88\%. As many as 17,000 cases are found every year. ${ }^{6}$ Meanwhile, data from the South Sumatra HealthOffice, new leprosy cases in children in 2017 amountedto 8.3\%, in 2018 it was $6.3 \%$, and in 2019 it was $7.3 \%$. When compared to the proportion of new leprosy patients in Indonesia, the figure obtained in this studyis relatively lower (7.58\%). In this research, during thelast 4 years, there has been a decrease in new cases ofleprosy.

Leprosy can occur at any age from infancy to old age. In chronic diseases such as leprosy, disease prevalence rates by age group do not reflect the risk of certain age groups to develop the disease. ${ }^{1}$ A systematicreview shows leprosy in children occurs with the highest frequency in 10-14 year-olds. The frequency ishigher in older age due to the long incubation period ofleprosy (5-7 years), delay in the diagnosis of initial lesions, and difficulty in assessing sensory loss in earlychildhood. 7 The youngest patient diagnosed with leprosy was 3 weeks old. 8 Brubaker et al reported that 91 infants under 1 year of age were diagnosed with leprosy. In this study, the youngest age of new leprosypatients was 3 years, and the 15-17 age group was thelargest (40\%).

In this study, the sex distribution of new patients aged 0-17 years, namely the number of men (60\%) more than women $(40 \%)$ or the ratio of male to female patients was 1.5: 1. Gitte et al also reported 551 new cases of leprosy in children aged $<18$ years, with a higher number of men (57\%) in PB type leprosy and 61.1\% in MB type leprosy.9

Differences in the prevalence of men and women may be affected opportunities for contact and social factors. Men tend to have more activities outside the home so that they are more often exposed to patients who are the source of infection so that the risk of contracting leprosy is greater than women. The low incidence of leprosy in women is probably due to environmental and socio- cultural factors. 10

This study showed that MB patients, especially BL type $(60 \%)$, were much more than PB patients. MB patients were found to be more male and the age group 15-17 years. The longer incubation period for MB type than PB type explains this relationship. ${ }^{11}$ Pinto et al reported 18 cases of leprosy in children, $66.7 \%$ of which were the MB type. 4 The high incidence of leprosy in children, especially the MB type, needs attention because of the MB type. is the main source of transmission. Type BL dominates pediatric leprosy patients, so the knowledge of the possibility of leprosy reactions needs to be informed, especially to the patient's parents.

Leprosy is referred to as an immunologic disease. ${ }^{1}$ The clinical manifestations are more proportional to the rate of cellular reactions than the intensity of the infection. The immunological response to $M$. leprae consists of two components, namely the innate and acquired immune response. The innate immune response is determined by genetic factors, including the PARK2/PACRG allele gene, the HLA gene on chromosome 6 with multiple alleles, and the non-HLA gene DR2.12 Monocytes/cells of dendritic origin are important mediators in the etiopathogenesis of leprosy. The cellular immune response is controlled by tumor necrosis factoralpha, interleukin (IL) 10, vitamin D receptors, and PARK2.5 Individuals susceptible to $\mathrm{M}$. leprae may experience broad clinical manifestations, depending on the host's ability to enhance the acquired immune response to infection.

When Mycobacterium leprae enters through inhalation and direct contact with the patient, the body will release macrophages for phagocytosis. Schwann cells are the target cells for the growth of Mycobacterium leprae. If there are an impaired body immunity and Schwann cells, the bacilli can migrate and activate, as a result, the activity of nerve regeneration is reduced and there is progressive nerve damage. 13

Nerve damage can occur in three stages, namely at the cutaneous stage at the affected nerve endings, at the subcutaneous stage, and in the nerve trunk. The histopathology of tuberculoid leprosy shows the form of granulomas in the dermis and papillae of the 
dermis. The granulomatous infiltrates damage the nerveendings in the papillae. In borderline leprosy, the nerves from the lower dermis and around the adnexa are most commonly affected. Granuloma formationcoincides with the proliferation of Schwann cells in andaround the perineurium. Damage due to compression of nerve fibers by epithelioid granulomas. During the reaction, edema formation occurs, and granulomas that expand causing continued nerve damage. Extracellular edema accumulates in the thickened perineurial sheath, compressing axons. Themechanisms that occur in the nerve trunks and subcutaneous nerves are more complex. 13

Skin and nerve manifestations were seen in both $\mathrm{PB}$ and MB types. Nerve disorders are found in the form of thickening of the nerves with or without pain and loss of sensation. Nerve thickening occurs in $60 \%-80 \%$ of pediatric patients. ${ }^{2}$ Gitte reported that out of 551 children with leprosy aged $<18$ years, most had symptoms of hypopigmented patches, and $4.3 \%$ had peripheral nerve disorders. $80.94 \%$ did not have neurological disorders. ${ }^{9}$ In this study, the manifestations of skin abnormalities in the form of hyperpigmented patches and erythematous nodules were found mostly in BL type of 3 people (30\%). Nerve function disorders were found in 5 people. Sensory disorder in the form of hypesthesia in one type BL patient. Sensory and motoric nerve function disorders occurred in 2 BL type patients, and 1 person $(11.11 \%)$ each in LL and TT types.

Nerve damage that causes permanent disability and disability is still a major problem in the course of leprosy infection. Children with permanent disabilities experience many difficulties in education, social life, and daily activities. The main reason is a lack of awareness and knowledge, which often causes a large delay in diagnosis. Nerve damage can occur before treatment, during treatment, and even in posttreatment patients. In borderline leprosy (BT, BB, and $\mathrm{BL})$ the damage is severe if a type 1 leprosy reaction occurs. If it occurs, the peripheral nerve trunks experience edema and tenderness, showing a decrease in function, which gradually over several days or even months until it becomes irreversible. In lepromatous leprosy (BL, and LL) the damage takes years but can increase suddenly during type 2 leprosy reactions. ${ }^{13}$

The prevalence of leprosy disability in children in India varies from $0.5 \%$ to $40.7 \%$. The presence of thickened nerves, older child age, and MB type leprosy significantly increase the risk of disability. Children with thickened nerves had 6.1 times higher risk of causing disability than did not have enlarged nerves. Gitte's study found leprosy defects in $19.9 \%$ of cases of children, with level 1 leprosy disabilities in 2.7\% of MB types and grade 2 leprosy disabilities in 19.5\% of MB types. 9 In this study There are 5 people (50\%) with level 0 leprosy disabilities. There are 5 people with level 1 leprosy, 3 each (30\%) with BL type, 1 person (10\%) with TT type, and 1 person (10\%) type LL. There were no patients with grade 2 disabilities.

The leprosy reaction is an acute/subacute inflammatory process, mediated by $\mathrm{T}$ lymphocytes or by antibodies, which occur before, during, and after treatment. Precipitating factors can be MDT, infections, parasitic infestations, vaccinations, emotional stress and should be considered when treating reactions. Type 1 reactions result from spontaneous increases in cellular immunity and delayed-type hypersensitivity to the $M$. leprae antigen. Type 2 reactions or erythema nodosum leprosum are mediated by immunecomplexes and proinflammatory cytokines. In pediatricleprosy, episodes of reaction and disability are seen less frequently. The leprosy reaction in children was reported as $3.1 \%-33.9 \%$. In adults more than $50 \%$ of patients experience reactions. Bandeira et al reported 34 leprosy patients aged $<15$ years in Brazil, $77.8 \%$ of patients had type 1 reactions, and $33.3 \%$ of patients had type 2 reactions, complications in the form of disability, and Cushing's syndrome. ${ }^{14}$ In this study, a total of 6 people (60\%) experienced no reaction. Type 2 reactions occurred in 3 people (30\%) of the BL leprosy type, and Lucio phenomena in 1 person (10\%) of the LL leprosy type. Reactions must be diagnosed early and managed appropriately if permanent disability is to be avoided. Ideally, the reaction should not occur at all, because it can be prevented by treatment. 13

The study by Gitte et al. reported that $56 \%$ of patients had a length of illness from 13 to 14 months, 
starting from complaints to seeking treatment. ${ }^{9}$ While this study showed the duration of illness from complaints to treatment for 6-12 months occurred in 5 people (50\%), by having a level 1 disability as many as 3 people (30\%). The delay in treatment comes from the lack of awareness of leprosy sufferers of the symptoms of leprosy, so delaying treatment has an impact on disability on lepers. Delays in treatment for leprosy patients are associated with higher rates of permanent nerve damage and disability. ${ }^{8}$ Leprosy patients who experience a delay in treatment for more than 1 year will experience an increase in the disorder by $10 \%$ $15 \%$, and delay in treatment within 2 years can cause an increase of $15 \%-25 \%$ in leprosy disabilities. ${ }^{14}$

The main source of infection in children is family contacts who have leprosy. ${ }^{15}$ The risk of contracting leprosy to a person is four fold when there is environmental contact. However, this risk increases to ninefold when the contact is in the family. The risk is higher (up to 14 fold) when contact with patients with multibacillary type leprosy, especially lepromatous. Detection of leprosy cases in children can be used to detect cases in the family, even in the community. Kumar et al reported the prevalence of family contacts in pediatric leprosy in the range of $10 \%-36 \%$. Gitte reported that $77.3 \%$ had a history of family contacts, especially mothers (11\%). 9 Similar to this study, the distribution of history and sources of contacts for new pediatric leprosy patients showed that $30 \%$ of patients had a history of household contacts.

In this study, $70 \%$ of the patients were domiciled in Palembang and 30\% were from outside Palembang, 2 patients were domiciled in Musi Banyuasin, and 1 patient in Ogan Komering Ulu. Similar research by Nery et al. concerning new cases of leprosy in childrenwho live in cities is more frequently reported (81\%) thanthose who live in villages. ${ }^{16}$ There is a difference in the number of leprosy cases based on geographic location within a country. Differences were observed between urban and rural communities. This was due to the correlation between high levels of knowledge among urban patients seeking treatment. Educational factors have a significant relationship with seeking treatment in leprosy patients. 16
Multidrug therapy (MDT) are the main therapy for leprosy. The decline in the prevalence of leprosy cases of more than $85 \%$ occurred within 20 years after MDT was recognized as a leprosy treatment. Drug recommendations for 6 months in PB leprosy cases and 12 months in MB cases. Parental education is important before starting MDT for children. The dosage regimen for MDT $\mathrm{PB}$ and $\mathrm{MB}$ children was based on different age groups. In children $<10$ years, the dose is calculated according to body weight. The doses of dapsone $1 \mathrm{mg} / \mathrm{kg} /$ day, rifampicin 10-20 mg/kg/day (<600 mg), and clofazimine $1 \mathrm{mg} / \mathrm{kg} /$ day. 5 The drugs are well tolerated by children. The drop out rate in children ranges from $10 \%$ to $20 \%$, the main cause is that children refuse to swallow tablets. In this study, all leprosy patients had never had a previous history of treatment. Treatment with MDT PB was given to 3 people (30\%), and MDT MB to 7 people (70\%).

Leprosy in children does not only have an impact on children's health like other diseases. Sufferers are often stigmatized, bullied, and shunned for life. Planning to reduce the incidence of leprosy and complications in children must be a top priority. Active and passive patient findings should be routinely carried out to avoid delays in diagnosis and management. Routine school surveys and annual contact surveys for early detection of cases are important tools in achieving the goal of eliminating leprosy. 17

There are some limitations in this study. This study was only conducted on 10 subjects. Further studies with a larger sample size are necessary to identify profile leprosy in children.

In conclusion, this study found that the incidence of leprosy in children aged 0-17 years at theDermatology and Venereology Polyclinic, Dr. Moh. Hoesin Palembang during the period January 2017 to December 2020 decreased than global case $(7.58 \%)$. Based on gender, it was found that there were more male patients than female. Manifestations of hyperpigmented skin patches and nervous disorders, grade 1 defects, and type 2 leprosy reactions are mostly found in type BL leprosy. The majority of patientsdomicile in the city of Palembang, and $30 \%$ have a history of positive contact from household members. Multidrug therapy and precautions need attention to break the chain of transmission and achieve zero disease elimination. 


\section{Conflicts of Interest}

The authors affirm no conflict of interest in this study.

\section{Funding Sources}

The author received no specific funding for this research.

\section{Acknowledgment}

The authors would like to thank the colleagues from Department of Dermatology and Venereology, Faculty of Medicine, Sriwijaya University, Dr. Mohammad Hoesin Hospital, Palembang, Indonesia, that greatly accomodated and assisted in sampling.

\section{References}

1. Salgado CG, Brito AC, Salgado UI SJ. Leprosy. In: Kang S, Amagai M, Bruckner AL, Enk AH, Margolis DJ, McMichael AJ OJ, editor. Fitzpatrick's Dermatology. 9th ed. New York: McGraw-Hill Company; 2019. p. 2892-990.

2. World Health Organization. Global leprosy (Hansen disease) update, 2019: time to step-up prevention initiatives. Wkly Epidemiol Rec. 2020;36(95):417-40.

3. Wibawa T, Satoto TBT. Magnitude of Neglected Tropical Diseases in Indonesia at Postmillennium Development Goals Era. J Trop Med. 2016;1-9.

4. Pinto ACVD, Wachholz PA, da Silva GV, MasudaPY. Profile of leprosy in children under 15 years of age monitored in a Brazilian referral center (2004-2012). An Bras Dermatol. 2017;92(4):580-2.

5. Maymone MBC, Venkatesh S, Laughter M, Abdat R, Hugh J, Dacso MM, et al. Leprosy: Treatment and management of complications. JAm Acad Dermatol. 2020;83:17-30.

6. Oktaria S, Hurif NS, Naim W, Thio HB, Nijsten TEC, Richardus JH. Dietary diversity and poverty as risk factors for leprosy in Indonesia: A case-control study. PLoS Negl Trop Dis. 2018;12(3):1-15.

7. Vieira MCA, Nery JS, Paixão ES, Freitas de Andrade KV, Oliveira Penna G, Teixeira MG. Leprosy in children under 15 years of age in Brazil: A systematic review of the literature. PLoS Negl Trop Dis. 2018;12(10):1-13.

8. Philip M, Samson JF, Ebenezer S. A ten year study of pediatric leprosy cases in a tertiary care centre in South Kerala. Indian $\mathrm{J}$ Lepr. 2018;90:95-9.

9. Gitte SV, Ramanath N S, Kamble KM. Childhood leprosy in an endemic area of central India. Indian Ped. 2016;53:221-4.

10. Liu YY, Yu MW, Ning Y, Wang H. A study on gender differences in newly detected leprosy cases in Sichuan, China, 2000-2015. Int $\mathrm{J}$ Dermatol. 2018;1-8.

11. Gaschignard J, Grant AV, Thuc N Van, Orlova M, Cobat A, Huong NT, et al. Pauci- and Multibacillary Leprosy: Two Distinct, Genetically Neglected Diseases. PLoS Negl Trop Dis. $2016 ; 10(5): 1-20$.

12. Uaska Sartori PV, Penna GO, Bührer-Sékula S, Pontes MAA, Gonçalves HS, Cruz R, et al. Human Genetic Susceptibility of Leprosy Recurrence. Sci Rep. 2020;10(1284):1-5.

13. Naafs B NS. Reactions in Leprosy. In: Nunzi E MC, editor. Leprosy. 1st ed. Italia: SpringerVerlag; 2012. p. 219-67.

14. Bandeira SS, Pires CA, Quaresma JAS. Leprosy reactions in childhood: A prospective cohort study in the Brazilian amazon. Inf Drug Resist. 2019;12:3249-57.

15. Teixeira CSS, Pescarini JM, Alves FJO, Nery JS, Sanchez MN, Teles C, et al. Incidence of and Factors Associated with Leprosy among Household Contacts of Patients with Leprosy in Brazil. JAMA Dermatol. 2020;653:1-10. 
16. Nery JS, Ramond A, Pescarini JM, Alves A, Strina A, Ichihara MY, et al. Socioeconomic determinants of leprosy new case detection in the 100 Million Brazilian Cohort: a population- based linkage study. Lancet Glob Heal. 2019;7(9).

17. Pedrosa VL, Dias LC, Galban E, Leturiondo A, Palheta J, Santos M, et al. Leprosy among schoolchildren in the Amazon region: A crosssectional study of active search and possible source of infection by contact tracing. PLoS Negl Trop Dis. 2018;12(2):1-12. 